\title{
Is Glutamine Responsible for the Radiosensitivity of Subthalamic Nucleus?
}

\author{
Manjul Tripathi ${ }^{a}$ Sonikpreet Aulakh ${ }^{b}$ \\ aDepartment of Neurosurgery, Postgraduate Institute of Medical Education and Research, Chandigarh, India; \\ ${ }^{\mathrm{b}}$ Translational Neuro-Oncology, West Virginia Cancer Institute, West Virginia University, Morgantown, WV, USA
}

Sir,

I have read with great interest the article by Drummond et al. [1] "Subthalamic Gamma Knife Radiosurgery in Parkinson's Disease: A Cautionary Tale.” The article details the preliminary results of gamma knife radiosurgery (GKRS) of the subthalamic nucleus (STN) for medically refractory Parkinson's disorder (PD). The authors planned GK subthalamotomy in 20 patients, with the primary endpoint being the safety of the procedure. They included 4 patients out of which, 3 demonstrated a hyperresponse in the targeted area on the follow-up imaging with corresponding neurological deterioration. All patients were unsuitable candidates for invasive surgical procedures such as deep brain stimulation or radiofrequency lesioning, hence, chosen for GK subthalamotomy as a bailout procedure though with dismal results after 12-month post-procedure [1].

For deep brain stimulation or radiofrequency lesioning, the targets may be STN, globus pallidus interna (Gpi), or ventral intermediate nucleus of thalamus (VIM) as per the predominant clinical symptomatology. The senior radiosurgeon of the group (Dr. Douglas S Kondziolka) has already highlighted excellent results with GK thalamotomy (in tremor predominant Parkinson's) [2] and mixed results with GK pallidotomy (in dystonia predominant

karger@karger.com

(c) 2020 S. Karger AG, Basel

www.karger.com/sfn

Karger!
Parkinson's patients) [3]. In my personal experience with GK pallidotomy for dystonias, the results were unpredictable as a hyper-response is much more frequent with GK pallidotomy than VIM thalamotomy $[4,5]$. VIM is considered a safer target than Gpi. Gpi has higher iron content, which might be the reason for higher radiosensitivity. Another possible reason is lenticulostriate arteries in the pallidum, which show an unpredictable occlusive response to the radiation.

The authors indirectly conclude that the only safe target left for radiosurgical management of PD is VIM [1]. The authors have tried to propose their hypothesis for hyper-response and radiation sensitivity. They purposely reduced the dose to $110-120$ Gy at $100 \%$ isodose to mitigate the radiation toxicity, yet complications were seen. Hence, the hyper-response is probably because of the hypersensitivity of STN rather than a dose-effect. STN is the only excitatory glutaminergic structure of basal ganglia [6]. Glutamine is a radiosensitizer, and previous publications have shown that glutamine derives glutathione synthesis that contributes to the radiation sensitivity of cancer cell lines. The inhibition of glutaminase markedly radiosensitized the lung cancer cell lines and pancreatic cancer stem cells, suggesting an important role of glutamine derived glutathione in determining radiosensitivity 
[7-10]. At present, there is no functional or metabolic imaging to quantify the level of glutamine or the activity of glutaminase, in the subthalamic nucleus in the normal or PD population. It would be interesting to note that quantification of this value may throw some insight into the future patient selection.

Though the results are grossly poor with a cautionary tale, this article is a valuable addition to the radiosurgical literature. The history of functional neurosurgery and psychosurgery has more oops than wow moments. However, the targets can be determined and preferred to others only after practical experiences. The same led us to the target selection in the stimulation surgeries over the last 3 decades, and many more are being explored daily. This article is a valuable adjunct to the functional radiosurgery, which would help us decide the treatment with primum nil nocere.

\section{Conflict of Interests Statement}

The authors have no conflicts of interest to disclose.

\section{Funding Sources}

The authors have no conflicts of interest to disclose.

\section{Author Contributions}

M.T.: concept, article draft, review, administrative support and S.A.: critically revising the article and literature review.

\section{References}

1 Drummond PS, Pourfar MH, Hill TC, Mogilner AY, Kondziolka DS. Subthalamic gamma knife radiosurgery in Parkinson's disease: a cautionary tale. Stereotact Funct Neurosurg. 2020;98(2):110-7.

2 Kondziolka D, Ong JG, Lee JY, Moore RY, Flickinger JC, Lunsford LD. Gamma knife thalamotomy for essential tremor. J Neurosurg. 2008 Jan;108(1):111-7.

3 Duma CM. Movement disorder radiosurgery: planning, physics and complication avoidance. Prog Neurol Surg. 2007;20:249-66.

4 Tripathi M, Sharan S, Mehta S, Deora H, Yagnick NS, Kumar N, et al. Gamma knife radiosurgical pallidotomy for dystonia: not a fallen angel. Neurol India. 2019 Nov-Dec;67(6):1515-8.
5 Tripathi M, Mehta S, Singla R, Ahuja CK, Tandalya N, Tuleasca C, et al. Vim stereotactic radiosurgical thalamotomy for drug-resistant idiopathic holmes tremor: a case report. Acta Neurochir. 2020.

6 Buchanan RJ, Darrow DP, Meier KT, Robinson J, Schiehser DM, Glahn DC, et al. Changes in GABA and glutamate concentrations during memory tasks in patients with Parkinson's disease undergoing DBS surgery. Front Hum Neurosci. 2014;8:81; .

7 Clark EP, Epp ER, Morse-Gaudio M, Biaglow JE. The role of glutathione in the aerobic radioresponse. I. Sensitization and recovery in the absence of intracellular glutathione. Radiat Res. 1986;108(3):238-50.
8 Sappington DR, Siegel ER, Hiatt G, Desai A, Penney RB, Jamshidi-Parsian A, et al. Glutamine drives glutathione synthesis and contributes to radiation sensitivity of A549 and H460 lung cancer cell lines. Biochim Biophys Acta. 2016;1860(4):836-43.

9 Patel C, Bernstein M, Hoeksema M, Massion P. Targeting glutamine metabolism to improve radiation sensitivity in non-small cell lung cancer. Int J Rad Oncol 2017;99;E613.

10 Li D, Fu Z, Chen R, Zhao X, Zhou Y, Zeng B, et al. Inhibition of glutamine metabolism counteracts pancreatic cancer stem cell features and sensitizes cells to radiotherapy. Oncotarget. 2015;6(31):31151-63. 